\title{
Performance Study of a Domestic Boiler Fueled By Biodiesel Produced From Rapeseed
}

\author{
Mohammad A. Hamdan* and Derar A. Almomani \\ Faculty of Engineering and Technology, The University of Jordan, Jordan
}

\begin{abstract}
A domestic boiler was used in this work to compare its performance when it is powered by diesel fuel and biodiesel fuel that is produced from rapeseed oil, then blends of both fuels were prepared with different concentrations of biofuel (B5, B10 and B20). The performance measurements included the efficiency of the boiler, the specific fuel consumption in addition to the environmental impact represented by exhaust gases analysis; this included the concentration measurements of main species such as $\mathrm{NOX}, \mathrm{NO} 2, \mathrm{NO}, \mathrm{SO} 2, \mathrm{CO} 2$ and hydrocarbon. It was found that there is a small decrease in boiler efficiency resulting from using biodiesel fuel. Moreover, an increase in the specific fuel consumption has been noticed. The performance of a domestic boiler when operating using B20, B5 and B10 blends has similar fuel consumption and efficiency when it is powered by petroleum diesel fuel. The regulated emissions from biodiesel fuel found to be more ecological than petroleum diesel, with the concentrations of all pollutants decrease with the percentages of biodiesel in the blends.
\end{abstract}

\section{Introduction}

The continuous volatility of petroleum price, the gradual decrease in the reserves of conventional energy resources, and the environmental problems created by the combustion of carbon based fuels, have placed great pressure on energy supplies to find solutions that cuts the energy bill, reduce the environmental impact of burning fossil fuel and improve the burning efficiency of the current combustion systems (Demirbas, 2009). There are several possible solutions to alleviate the problems of using fossil fuels, among such solutions involves the production of biodiesel fuel from different types of plant oil or fat[2] (Young, 2011).

Biodiesel produced from vegetable oils is attracting many countries to invest in and consequently built an integrated production unit and use it for commercial purposes, such as for electric power generation, operation of diesel engines and for use in boilers. Furthermore, and in general, Biodiesel is better than petroleum diesel for the environmental and has lower emissions than petroleum diesel when burned especially $\mathrm{CO}_{2}$, sulfur content and aromatic material, this led to minimize the greenhouse effect Also biodiesel is non-toxic and biodegradable (Demirbas, 2008),(Lapuerta, et al, 2008).

To prevent completion with food, biodiesel should be produced from non-food plants that will be grown on low quality arid lands and irrigated by low quality water. Although known for their vigorous growth, not all biodiesel plants are able to grow inarid lands and climates. Only a few were reported to be more than moderately salt tolerant ( Doornbosch, and Steenblik, 2008).

The impact of using biodiesel in internal combustion engine showed good result in regulated emissions which has been reduced the $\mathrm{CO}, \mathrm{SO}_{2}, \mathrm{CO}_{2}$ gasses and particulate matter about $50 \%$, but the $\mathrm{NO}_{\mathrm{x}}$ increase about $10 \%$. The solution to this problem has done by blends biodiesel with petroleum diesel at certain ratio like $\mathrm{B} 5, \mathrm{~B} 20, \mathrm{~B} 40$ and $\mathrm{B} 80$ (Lapuerta, et al, 2008),(Carraretto, et al, 2004).

${ }^{*}$ Corresponding author

E-mail: mhamdan@ju.edu.jo

(C) 2016 International Association for Sharing Knowledge and Sustainability

DOI: $10.5383 /$ ijtee.12.02.001 
Edible and non- edible oils are considered as important resources for producing biodiesel such as canola, soybean, palm, corn, jatropha, pongamia, pinnata and rapeseed oils. Nevertheless, the biodiesel crops need to be cost efficient and should not conflict with the food needs. (Lang, 2001), (Pramanik, et al, 2003), (Senthil Kumar, et al, 2003).

Biodiesel produced from waste vegetable oil and from soy also can be used in boiler and space heating; the efficiency does not change and the specific consumption increase due to lower heating value of biodiesel, boiler showed good result in regulated emissions which has been reduced the $\mathrm{CO}, \mathrm{SO}_{2}, \mathrm{CO}_{2}$ gasses and particulate matter but the $\mathrm{NO}_{\mathrm{x}}$ has been increased (Tashtoush, et al, 2004), (Lee, et al, 2004).

Rapeseed is a bright yellow flowering member of the family brassicaceas (mustard or cabbage family). It is currently grown using high level of nitrogen-containing fertilizers the manufacture of which generates nitrous oxide $\left(\mathrm{N}_{2} \mathrm{O}\right)$, an effective greenhouse gas. It has been estimated that about 3-5\% of the nitrogen supply in the fertilizers used to grow rapeseed is converted to $\left(\mathrm{N}_{2} \mathrm{O}\right)$ (Kumar, 1999).

(Bazooyar et.al., 2012) proved that the use of pure biodiesel (from edible vegetable oils) is not economically feasible for used in the boiler, so they used biodiesel-diesel blends with different ratio and they concluded that $\mathrm{B} 5$ is the best ratio due to cost and B20 is the best for emissions. The potentialities of biodiesel as an alternative fuel based on strategic considerations and field experiences in boilers has been presented by (Carraretto, et al., 2004). They concluded that Biodiesel from vegetable oil seems to be a promising solution for boilers, since only a few adjustments are required.

In Jordan, rapeseed seems to be a promising crop for biodiesel production, this is due to the fact that it is cultivated from drought/salt tolerant non-food plants that will be grown on low quality arid lands and irrigated by low quality water. In this study an attempt will be conducted to find new sources of energy in Jordan.

The main objective of this proposed work is to power a domestic boiler using biodiesel fuel extracted from a nonedible plant grows in Jordan called rapeseed. Once the boiler is set into operation using this fuel, its performance and the emitted pollutants will be measured and compared with those when pure diesel fuel was used to operate the boiler.

\section{Experimental wok}

A detailed experimental setup with descriptions of the used equipment is shown in Figure 1.

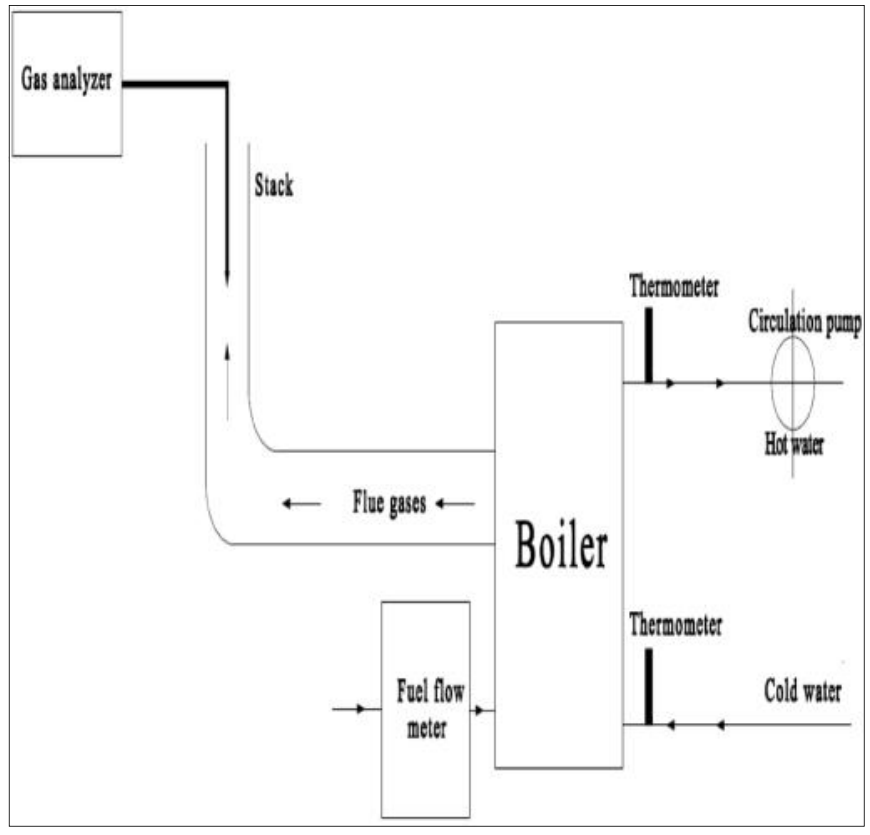

Fig. 1 Experimental Setup

As indicated the main components are:

1. A BiasiB-10 boiler with maximum heating capacity of $75 \mathrm{~kW}$ with efficiency in the range between 85.8 to $87.2 \%$ and with water content equals to 3.7 Gallons.

2. The burner with model number ST120, which has fuel consumption value of $2-5 \mathrm{~kg} / \mathrm{h}$ with output power $24-$ $60 \mathrm{~kW}$. The recommended pump pressure is 10 bar with viscosity range $1.3-12 \mathrm{~mm}^{2} / \mathrm{s}$.

3. A Wilo Circulation pump with model number Star-RS 25/4 RG. It has a maximum delivery head equals to 4 (m) with maximum volume flow rate about $3.5\left(\mathrm{~m}^{3} / \mathrm{h}\right)$. The main frequency equals $50 \mathrm{~Hz}$ and the diameter of pipe connection equals $1 "$.

4. Gas analyzer of type NOVAplus. This analyzer is a compact flue gas measuring instrument with wireless Remote Control Unit (RCU) for industrial applications. This device is capable to measure the exhaust emissions ( $\mathrm{NO}, \mathrm{NO}_{2}, \mathrm{NO}_{x}, \mathrm{SO}_{2}, \mathrm{CO}_{2}$ and hydrocarbon);

Having produced the biodiesel from rapeseed. This produced biodiesel was characterized by evaluating some of chemical and physical properties such as: Heating value, kinematic viscosity and density by using appropriate devices ( bomb calorimeter, viscometer ). The following table lists the physical measured properties of both pure diesel and the produced biodiesel 
Table 1 Properties of diesel and biodiesel

\begin{tabular}{|l|c|c|c|}
\hline Characteristic & Unit & Diesel & Biodiesel \\
\hline Density & $\mathrm{g} / \mathrm{ml}$ & 0.84 & 0.88 \\
\hline $\begin{array}{l}\text { Kinematic } \\
\text { Viscosity @ 40 C }\end{array}$ & $\mathrm{cSt} .\left(\mathrm{mm}^{2} / \mathrm{s}\right)$ & 3.5 & 5.1 \\
\hline Calorific value & $\mathrm{kJ} / \mathrm{kg}$ & 43472 & 39125 \\
\hline Acid Value & $\begin{array}{c}\mathrm{mg} \mathrm{KOH} / \mathrm{g} \\
\text { oil }\end{array}$ & $/$ & 0.46 \\
\hline $\begin{array}{l}\text { Soap content } \\
\text { oleate }\end{array}$ & $\mathrm{ppm} \mathrm{sodium}$ & $/$ & 210 \\
\hline Iodine Value & $\mathrm{g} / 100 \mathrm{~g}$ & $/$ & 84 \\
\hline Flash point & ${ }^{\circ} \mathrm{C}$ & 110 & 189.5 \\
\hline Ash content & $\%$ & 0.01 & 0.01 \\
\hline
\end{tabular}

The boiler was put into operation using pure diesel fuel, then the quantity of air introduced into the engine was varied such a stiochiometric conditions was achieved, which is indicated by the maximum values of temperature. Having reached steady state, the variation of efficiency and pollutants concentrations with time were recorded until these values of concentrations reach an almost constant values. This procedure was repeated when the boiler was powered by all blends. Same steps were followed using biodiesel fuel.

Using Air flow meter device (Anemometer) the air flowing into burner was measured. While flow meter is used to measure fuel flow rate into the burner, then $\mathrm{A} / \mathrm{F}$ was found.

\section{Discussion of Results}

The variation of thermal efficiency of the boiler with the amount of excess air supplied is shown in Figure 2. As it may be noticed from this Figure the thermal efficiency of the boiler once powered by biofuel is less that that when it is powered by pure diesel fuel, this is attributed to the fact the heating value of the biofuel is less than that of pure diesel. Further, it may oticed from this Figure that the maximum efficiency of boiler when powered by biofuel is achieved with higher amount of airbeing supplied to the boiler that the case of pure diesel, this due to the fact that biofuel is of higher viscosity than diesel fuel and hence it requires more air for complete combustion

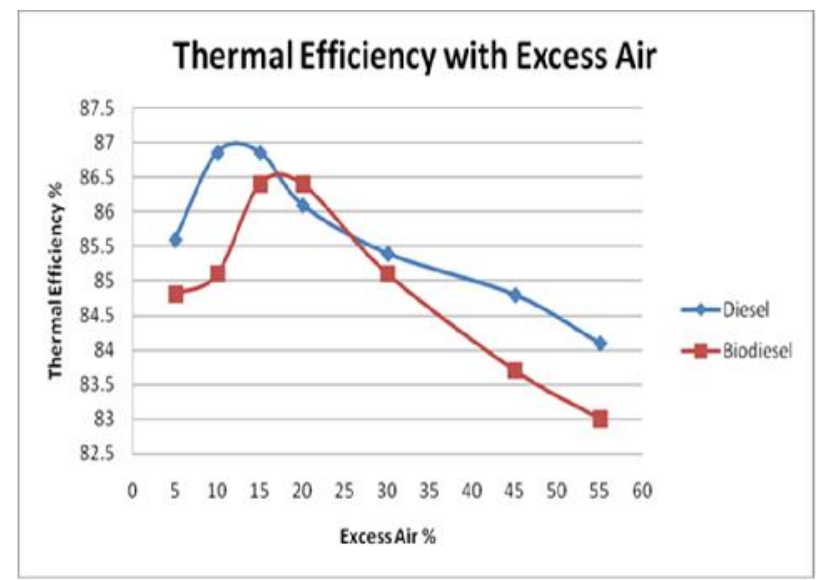

Figure 2: Variation of Thermal Efficacy with Excess Air
The variation of NOx with excess air is shown in Figure 3. As indicated the amount of NOx emitted was increased with excess air for both fuels until the stoichiometric condition is achieved, beyond which the emitted amounts of $\mathrm{NO}_{\mathrm{x}}$ starts to decrease. This behavior is due the increase in temperature as the combustible mixture approaches the stoichiometric conditions. As the amount of increase beyond this conditions the temperature starts to decrease.

It is to be noted from this Figure that the amount of NOx emitted from the burning of biofuel is less that emitted during the combustion of pure diesel fuel, this is attributed to the fact that the temperature within the combustion chamber when diesel fuel is burned is higher that it when biofuel is burned, in addition diesel fuel usually contains more nitrogen compound than biofuel does. Upon combustion these nitrogen bounded compounds liberate nitrogen element leading to the formation of $\mathrm{NO}_{\mathrm{x}}$

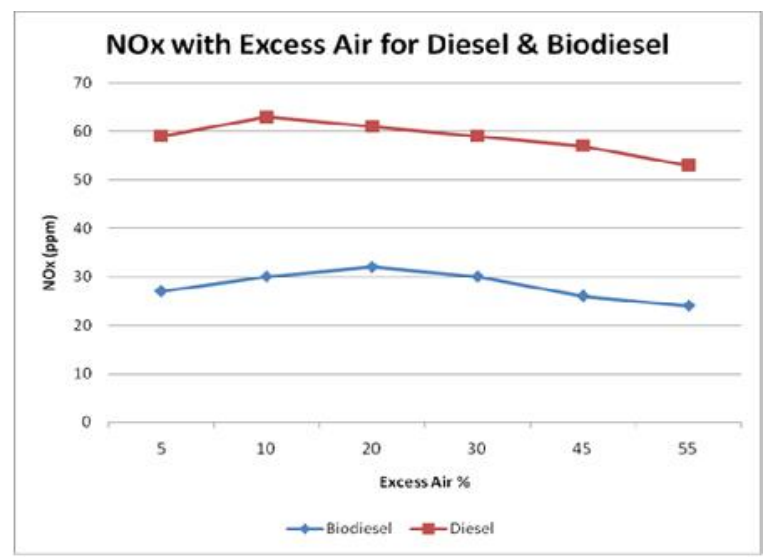

Figure 3: $\mathrm{NO}_{\mathrm{x}}$ Gas with Excess Air for Diesel \& Biodiesel

The emitted amounts of $\mathrm{SO}_{\mathrm{x}}$ gas from the burning of both fuels are shown in Figure 4. As indicated the $\mathrm{SO}_{2}$ concentration did not change with excess air because the concentrations of sulfur oxides $\left(\mathrm{SO}_{\mathrm{x}}\right)$ depends on the amount of sulfur compounds contained within the fuel as impurities. As indicated and as expected, $\mathrm{SO}_{\mathrm{x}}$ emitted from pure diesel significantly exceeds that emited from biofuel, which is due to the fact Jordanian diesel fuel is characterized by relatively high contents of sulfur, while produced biofuel is almost sulfur free one.

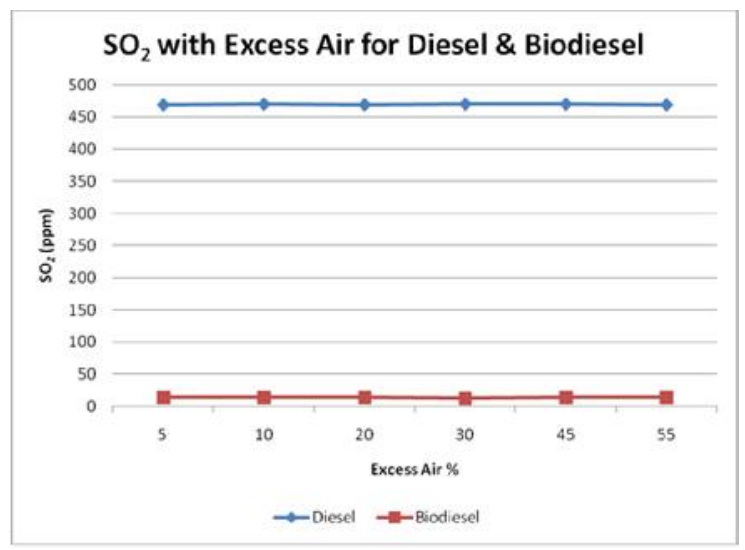

Figure 4: $\mathrm{SO}_{2}$ Gas with Excess Air for Diesel \& Biodiesel 
The variation of emitted carbon dioxide with excess air is presented in Figure 5, from which it may be noticed that initially the concentration of $\mathrm{CO}_{2}$ increases with excess air to a maximum values and start to decrease with excess air, this due to the fact that the combustion process under rich mixture leads to incomplete combustion and hence low concentration of $\mathrm{CO}_{2}$. As the amount of supplied air increase, the combustion process proceeds and complete combustion condition is achieved leading to high emitted values of $\mathrm{CO}_{2}$. As the amount of excess air gets large the combustion process proceeds under lean conditions, which is less intense and hence emitted $\mathrm{CO}_{2}$ decreases.

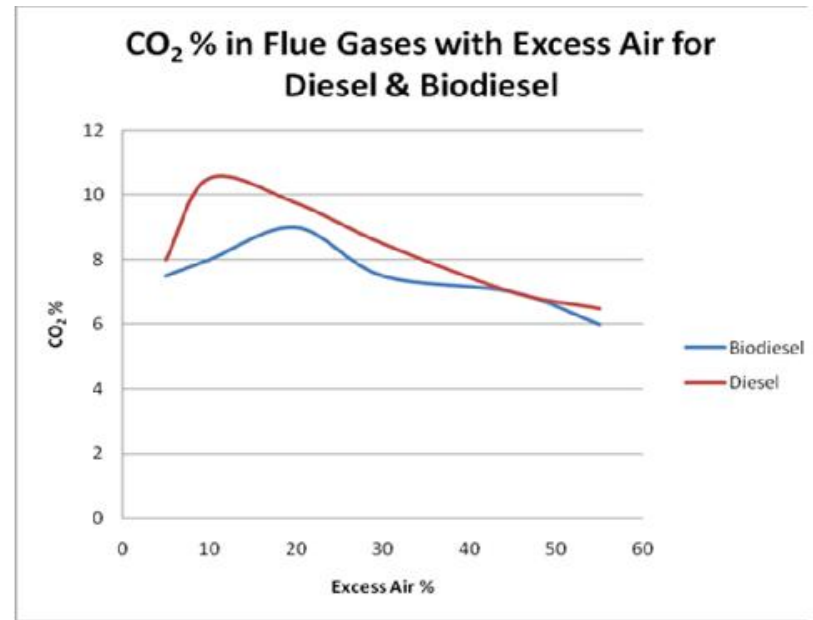

Figure 12: $\mathrm{CO}_{2}$ Gas with Excess Air for Diesel \& Biodiesel

\section{Conclusion}

From this study the following may be concluded:

1. Biodiesel produced from rapeseed oil has higher density and kinematic viscosity than petroleum diesel in addition it has lower calorific value than diesel fuel.

2. The boiler performance results shows that a small decrease in boiler efficiency when using biodiesel fuel

3. The measured concentrations of main pollutant indicate that biodiesel is more environmental friendly than diesel fuel.

4. The stoichiometric point of excess air percent was $15 \%$ for biodiesel fuel and $10 \%$ for diesel fuel.

5. The biodiesel from rapeseed in Jordan seems to be of high potential as an alternate fuel for use in biodiesel production.

\section{References}

[1] Bazooyar, B., Ghorbani, A., \&Shariati, A. (2011). Combustion performance and emissions of petrodiesel and biodiesels based on various vegetable oils in a semi industrial boiler. Fuel, 90(10), 3078-3092.

[2] Carraretto, C., Macor, A., Mirandola, A., Stoppato, A., \&Tonon, S. (2004). Biodiesel as alternative fuel:
Experimental analysis and energetic evaluations.Energy, 29(12), 2195-2211.

[3] Demirbas, A. (2008). Biodiesel (pp. 111-119). Springer London.

[4] Doornbosch, R., \&Steenblik, R. (2008). Biofuels: is the cure worse than the disease?. Revista Virtual REDESMA, 2, 63.

[5] Demirbas, A. (2009). Progress and recent trends in biodiesel fuels. Energy conversion and management, 50(1), 14-34.

[6] Ghorbani, A., \&Bazooyar, B. (2012). Optimization of the combustion of SOME (soybean oil methyl ester), B5, B10, B20 and petrodiesel in a semi industrial boiler. Energy.

[7] Kumar, P. R. (1999). Rapeseed mustard research in India: 21 st century strategies. In 10th International Rapeseed Congress, Canberra, Australia.

[8] Lapuerta, M., Armas, O., \& Rodriguez-Fernandez, J. (2008).Effect of biodiesel fuels on diesel engine emissions. Progress in energy and combustion science,34(2), 198-223.

[9] Lang, X., Dalai, A. K., Bakhshi, N. N., Reaney, M. J., \& Hertz, P. B. (2001). Preparation and characterization of bio-diesels from various biooils.Bioresource technology, 80(1), 53-62.

[10] Lee, S. W., Herage, T., \& Young, B. (2004). Emission reduction potential from the combustion of soy methyl ester fuel blended with petroleum distillate fuel.Fuel, 83(11), 1607-1613.

[11] No, S. Young. (2011). Inedible vegetable oils and their derivatives for alternative diesel fuels in CI engines: a review. Renewable and Sustainable Energy Reviews, 15(1), 131-149.

[12] Pramanik, K. (2003). Properties and use of Jatrophacurcas oil and diesel fuel blends in compression ignition engine. Renewable energy, 28(2), 239-248.

[13] Senthil Kumar, M., Ramesh, A., \&Nagalingam, B. (2003). An experimental comparison of methods to use methanol and Jatropha oil in a compression ignition engine. biomass and bioenergy, 25(3), 309318.

[14] Tashtoush, G., Al-Widyan, M. I., \& Al-Shyoukh, A. O. (2003). Combustion performance and emissions of ethyl ester of a waste vegetable oil in a water-cooled furnace. Applied Thermal Engineering, 23(3), 285293. 